\title{
Per la difesa della cultura. Scrittori a Parigi nel 1935, a cura di Sandra Teroni
}

\section{Emanuele Kanceff}

\section{(2) OpenEdition}

1 Journals

\section{Edizione digitale}

URL: http://journals.openedition.org/studifrancesi/35072

DOI: $10.4000 /$ studifrancesi.35072

ISSN: 2421-5856

\section{Editore}

Rosenberg \& Sellier

\section{Edizione cartacea}

Data di pubblicazione: 1 novembre 2005

Paginazione: 444

ISSN: 0039-2944

\section{Notizia bibliografica digitale}

Emanuele Kanceff, «Per la difesa della cultura. Scrittori a Parigi nel 1935, a cura di Sandra Teroni», Studi Francesi [Online], 146 (XLIX | II) | 2005, online dal 30 novembre 2015, consultato il 20 avril 2021. URL: http://journals.openedition.org/studifrancesi/35072; DOI: https://doi.org/10.4000/studifrancesi. 35072

Questo documento è stato generato automaticamente il 20 avril 2021.

\section{(c) (1)}

Studi Francesi è distribuita con Licenza Creative Commons Attribuzione - Non commerciale - Non opere derivate 4.0 Internazionale. 


\title{
Per la difesa della cultura. Scrittori a Parigi nel 1935, a cura di Sandra Teroni
}

\author{
Emanuele Kanceff
}

\section{NOTIZIA}

AA. VV., Per la difesa della cultura. Scrittori a Parigi nel 1935, a cura di Sandra TERONI, Roma, Carocci Editore («Ricerche», 106. Letterature straniere) 2002, 223 pp.

1 Il libro evoca la riunione che ebbe luogo a Parigi, tra il 21 e il 25 giugno 1935, con il titolo di «Congrès international des écrivains pour la défense de la culture», promosso da un gruppo di scrittori francesi antifascisti, di varie tendenze politiche, cui parteciparono anche scrittori tedeschi in esilio e sovietici: La riunione ebbe un vivo successo e vide riuniti ben 230 delegati provenienti da 38 paesi. Tuttavia, la preparazione e lo svolgimento di questo evento internazionale furono segnati da non poche divergenze. La curatrice, Sandra Teroni, mette a punto la questione in una densa introduzione, evocando la meticolosa preparazione, la tensione in cui gli oratori si trovarono ad operare, i filoni di riflessione che si svilupparono e il programma di solidarietà internazionale che ne derivò, la nascitaz dell'Association internationale des écrivains e l'opera che le varie delegazioni svolsero. La raccolta di saggi è organizzata su quattro serie, che rispondono rispettivamente ai titoli «Convergenze d'intenti», «Diritto di sguardo e miraggi», «Da prospettive diverse» e «Alla ricerca di un ruolo». Diamo qui di seguito il dettaglio dei saggi pubblicati:

2 1. Giorgio Caredda, Il discorso antifascista in Francia; Claudio Natoli, Tra continuità e rinnovamento: la svolta nella politica del Comintern; Serge Wolikow, Il Partito comunista francese di fronte all'evento; Giannarita Mele, L'antefatto del 1934 e la controversa delegazione degli scrittori sovietici. 
3 2. Sandra Teroni, Difesa della cultura e problematico incontro fra culture; Marcello Flores, Immagini Dell'urss negli anni trenta: il ruolo degli intellettuali; Enzo Collotti, Gaetano Salvemini: una «nota stonata»; Marina Guglielmi, Immagini di mondo, immagini d'artista.

4 3. Luciano Marrocu, «I do believe in liberty»: voci della cultura inglese; Valentina Serra, La letteratura clandestina: il caso di Deutsch fur Deutsche; Maria Sechi, Riviste tedesche in Francia dal 1933 al 1939; Mariella Tinti Ladu, «Cet étrange congrès» sulla stampa coeva e nel ricordo di chi lo visse.

5 4. Sandro Maxia, Che fare di Westminster? La questione dell'eredità culturale; Annamaria Laserra, Ideologie e retoriche a confronto, Wolfgang Klein, «Non dovrebbero più esserci intellettuali»? Parigi 1935 e Lyotard 1983 rivisti oggi. Dopo una equilibrata postfazione di Remo Ceserani, sono da segnalarsi una preziosa Bibliografia degli interventi al «Congrès» del 1935 e un altrettanto prezioso indice dei nomi. 